\title{
USGS Releases New Digital Aerial Products
}

The U.S. Geological Survey (USGS) Center for Earth Resources Observation and Science (EROS) has initiated distribution of digital aerial photographic products produced by scanning or digitizing film from its historical aerial photography film archive. This archive, located in Sioux Falls, South Dakota, contains thousands of rolls of film that contain more than 8 million frames of historic aerial photographs. The largest portion of this archive consists of original film acquired by Federal agencies from the 1930s through the 1970s to produce 1:24,000-scale USGS topographic quadrangle maps. Most of this photography is reasonably large scale (USGS photography ranges from 1:8,000 to $1: 80,000)$ to support the production of the maps.

Two digital products are currently available for ordering: high-resolution scanned products and medium-resolution digitized products.

\section{High-Resolution Scanned Products}

High-resolution files (Figs. 3 and 4) are photogrammetric quality and generally created at approximately 1,200 dots per inch (dpi) with an output image size of around 9 inches square. File sizes are approximately 120 megabytes (MB) for black-

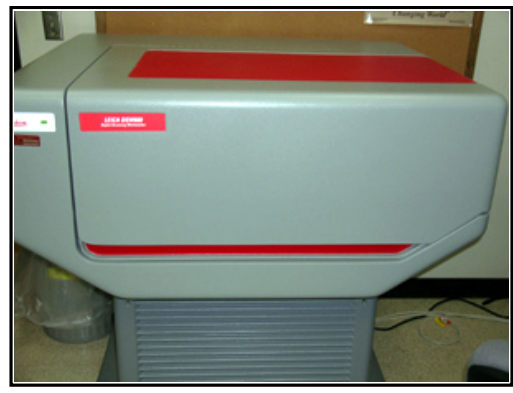

Figure 1. Leica Geosystems DSW600 and-white images and 360 MB for color images and are stored in a Tagged Image File Format (TIFF). High-resolution files are produced on either a Zeiss SCAI Precision Scanner using a Photogrammetric Digital Image Processing System (PHODIS) or on a Leica Geosystems DSW600 (Fig. 1) or DSW700 Digital Scanning Workstation. High-resolution scans of up to 3,600 dpi are available upon request.

\section{Medium-Resolution Digitized Products}

Medium-resolution files (Fig. 5) are non-photogrammetric quality and created at approximately 600 dpi with an output image size of around 5 inches square. File sizes are approximately $15 \mathrm{MB}$ for black-and-white images and $45 \mathrm{MB}$ for color images and are stored in a TIFF format. Medium-resolution files are produced using a Phoenix IV digitizing system (Fig. 2) with a digital camera and Adobe Photoshop software.

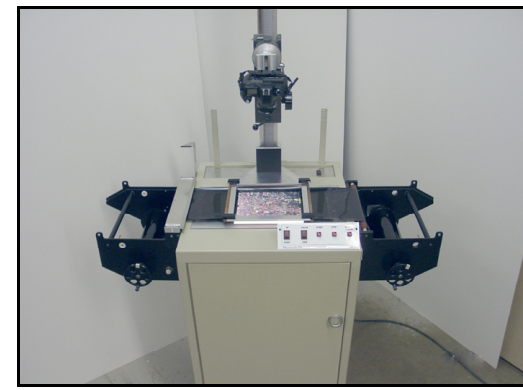

Figure 2. Phoenix IV digitizing system

\section{For More Information}

Samples of high-resolution and medium-resolution digital data for two frames of photography over an area of New York City taken in 1966 at a scale of 1:24,000 can be downloaded to your site using File Transfer Protocol (FTP) from the following location: http://edc.usgs.gov/phoenix_iv/new_york.

All National Aerial Photography Program (NAPP) data can be searched and ordered through Photofinder (a "quick and easy" search and order tool devoted solely to NAPP) at http://edc.usgs.gov/photofinder or through EarthExplorer at http://earthexplorer.usgs.gov/.

U.S. Geological Survey (USGS)

Center for Earth Resources

Observation and Science (EROS)

Customer Services

Mundt Federal Building

Sioux Falls, SD 57198-0001

Phone: 800-252-4547

Phone: 605-594-6151

TDD: 605-594-6933

Fax: 605-594-6589

Email: custserv@usgs.gov 


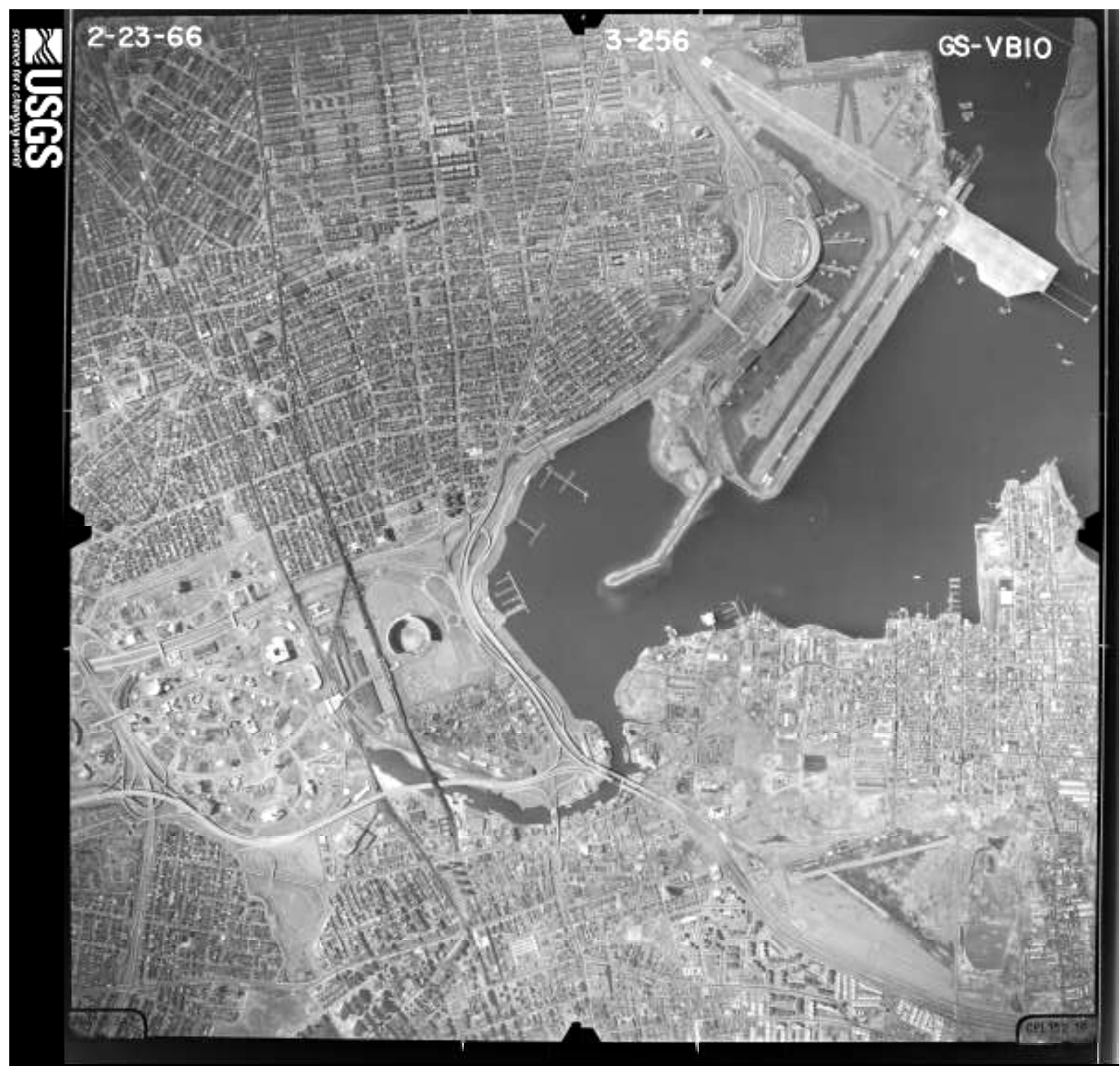

Figure 3. New York, New York, aircraft data flown in 1966

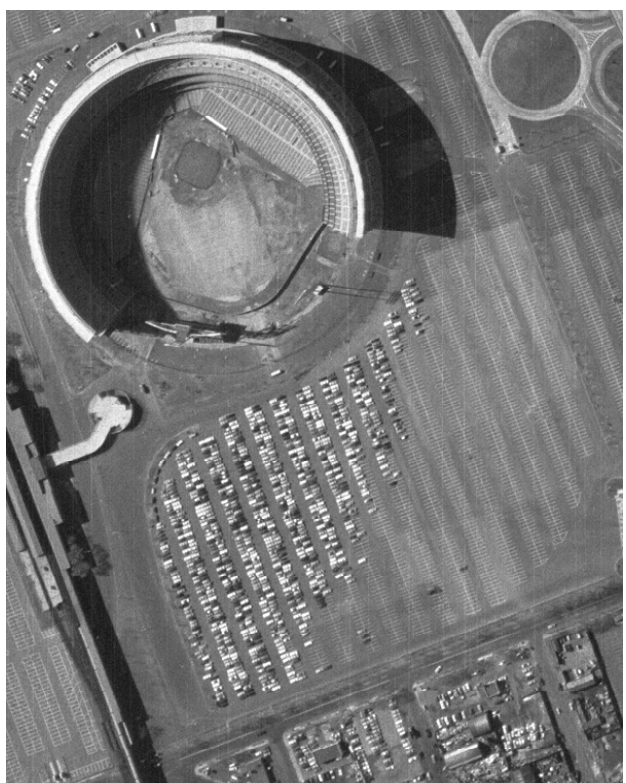

Figure 4. High-resolution scanned product

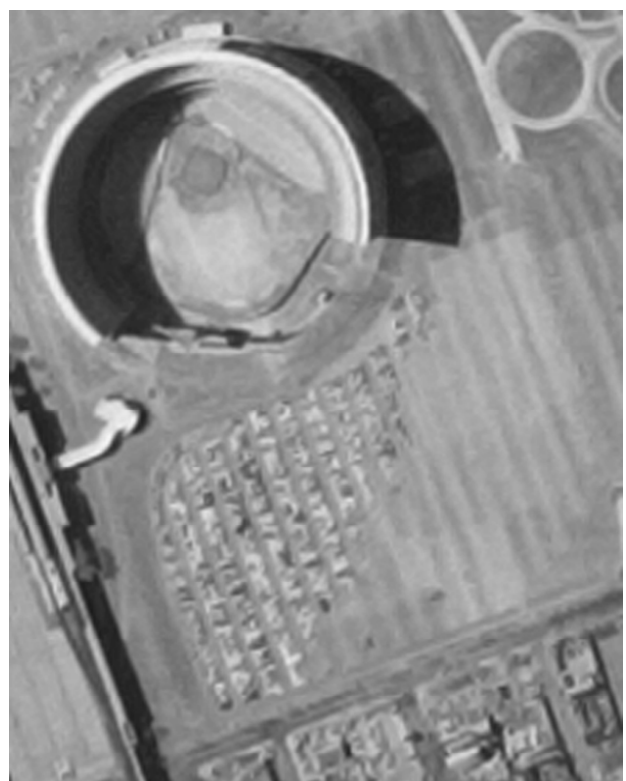

Figure 5. Medium-resolution digitized product 